\title{
Teacher Preparation: Coaching for Excellence
}

\author{
${ }^{1}$ Kerry E. Black, ${ }^{2}$ Sharon L. Moore \\ ${ }^{1}$ University of Alberta \\ ${ }^{2}$ Athabasca University \\ Canada
}

\begin{abstract}
What is the impact of coaching when used in teacher preparation field experiences? Traditional teacher preparation and mentor feedback centers on supporting teachers to develop the skills, knowledge and attributes required to become teachers in Alberta, Canada. Generally, a clinical supervision model is used to provide feedback and evaluate. However informative, a clinical supervision model is limited. This paper will describe the benefits of adding coaching to complement traditional supervisory approaches during student teacher's field experiences to engage them in reflection, clarify their purpose for teaching and align beliefs between theory and practice. Coaching provides an engaging, high impact experience that encourages the development of resilient and reflective teachers.
\end{abstract}

\section{Introduction}

Traditional supervision and assessment practice for teachers in the school system uses a clinical supervision model to observe the knowledge, skills and attributes needed of teachers, judged against the Teaching Quality Standard in the Province of Alberta. While this model is essential to observe the knowledge, skills and attitudes required for licensing, and is "tried and true", there are times when "something more" might address needs of a changing workforce and increase teacher retention. In Alberta, there is a current need for skilled teachers in trade areas such as auto mechanic, autobody, bakers, carpentry, culinary, cosmetology, electrical, welding/fabrication, heavy equipment operation and plumbing and refrigeration. Trades people working in these areas have much to offer in preparing High School students for careers in these trade areas. However, mature tradespeople may experience different challenges as they move into the teaching role, such as: the tension of moving from entrepreneur to teacher, their own experiences of being a "student", the expectations of the curriculum, and managing students.

In this paper we will describe the innovative Career and Technology Bridging Program [1] specific to the student teaching experience with a group of 8 mature, career change tradespeople engaged in preservice student teaching. The unique approach described in this paper involved the expertise of the pre-service field supervisor, (the "University Facilitator") who was also a University-trained Certified Coach.

Illustrated through the pre-service student teacher's reflective feedback, the impact of coaching as a supportive practice for growth and development during the 14 weeks of the student teaching experience will be described. Finally, we will offer suggestions about the impact of coaching in response to the pre-service students' experience.

\section{Background}

The Bridge to Teacher Certification program was initiated in 2010, to address complex forces within the Province of Alberta. These included: the increasing challenge of securing qualified tradespeople to teach High School Students (Grades 9-12, approximate ages 14-18) in the Career and Technology Studies curriculum and meet school division's collective agreements; the decreasing rate of High School graduation in a Province with a booming economy offering well-paying jobs in the trades available to individuals over the age of 16 (High School minimum leaving age), and the increasing learning complexity presented by students who may feel challenged by traditional academic learning and preparation, or the core curriculum.

To add to the pressure being placed on schools by students, workforce planning indicated anticipated teaching shortages due to retirement and attrition of new teachers, and few qualified teachers to work in the Career and Technology Studies areas of the curriculum.

In response to these challenges, Alberta Education created a program grant allowing School Divisions to sponsor tradespeople to attend University and train to become teachers, in areas of need. The University of Alberta was selected as best equipped to provide the program. The program provides in-depth pedagogy coursework held on campus in Edmonton, Alberta Canada. Pre-service fieldwork is provided in two focused experiences. The Introductory Field Experience (IFX) is held in the Fall semester, and has a duration of 5 weeks. The Advanced Field Experience (AFX) is held in the Winter semester, 
and is a 9 week immersion in teacher pre-service training.

At the end of their University training and with successful pre-service experiences, these tradespeople are granted Interim Certification, and can teach in the Province of Alberta with certain conditions, although they have not yet obtained a full Bachelor's Degree. The primary condition is that they are permitted to teach in their Trade Skill area only, until they have completed the full requirements of their teaching degree. They are expected to continue with their studies part time, to attain their Degree.

The remainder of this paper will discuss the experience of this group of tradespeople as they participated in their student teaching, "pre-service" experience. They will be referred to as pre-service teachers, in reference to their student teacher status.

\section{Adding Value}

A clinical supervision model for teacher evaluation and ongoing feedback is generally used as practice during the pre-service field experience, particularly by the University Facilitators, who are occasional observers in the pre-service teachers experience. Further, a clinical supervision model is commonly used by School Administrators when practicing teachers are being evaluated. During the field experience, the mentor teacher is the primary evaluator, mentor, and day-to-day support for the pre-service teacher. Expectations for mentor teachers do not specify the manner in which feedback is given. However, the guidelines for Mentor Teachers state that "Feedback should be descriptive and specific. Be clear on what the Student Teacher is doing well, as well as areas of potential growth. Feedback should be based on the Knowledge, Skills and Attributes required of students (as described in the evaluation documents)" [2].

When assessing and providing feedback during pre-service teaching practice, clinical supervision is seen as objective and data-driven, and the focus of the observation can be directed by the pre-service teacher. Clinical supervision can be described as a cyclical process. It is initiated by a discussion between pre-service teacher and observer/assessor to identify the purpose, context, and focus for the lesson observation. Outcomes for success are identified. The lesson is observed. During the observation, the observer/assessor collects data based on the identified lesson focus. Following the lesson, the observer/assessor and pre-service teacher discuss and reflect on the findings. The emphasis of clinical supervision is to identify, with data, practices that result in positive student learning outcomes, and make implementation recommendations to the preservice teacher. Most commonly, strategies are suggested or provided by the observer/assessor for implementation. Challenges of clinical supervision as a practice to improve teaching may include lack of ownership by the pre-service teacher to implement the changes, narrowed focus of observation that do not lead to the pre-service teacher's ability to uncover beliefs and values about teaching actions, and lack of awareness or ability to create reasoned consideration of next steps.

It is of note that the range of supervisory practices used by mentor teachers during field experiences is varied. The complexity of each classroom, combined with the mentor teacher's own background, beliefs, experience and personal expectations about their role lead to a wide variance in feedback to pre-service teachers. The variance may include a "hands-off" stance; verbal general observations following lessons; daily written reflective feedback; to an application of the clinical supervision process. These practices may or may not promote the pre-service teacher's growth in practice.

This diverse implementation of supervisory experience is seen throughout the experience of all pre-service practicum placements, and is not confined to pre-service trade teachers. During the 14 weeks of pre-service practicum, it was observed that the mentor teachers primarily used a verbal, observational daily reflection format. The scope of this paper limits the full discussion of supervisory practice used by mentor teachers, as they supervise pre-service trade teachers, and we believe that it is an area that warrants further investigation. It was apparent that there was a need for something more to assist these skilled tradespeople transitioning into the teaching role that would solidify their teaching skills. Coaching was seen to provide this additional support.

Coaching as a discipline is increasingly supported in business literature and supported by the International Coach Federation (ICF). The role of the coach is to "partner with clients in a thoughtprovoking and creative process that inspires them to maximize their personal and professional potential". [3] Certified coaches work with clients from many business and not for profit sectors. Coaching is particularly well aligned to the complex work of the "helping professions" such as Education. The ICF is recognized worldwide, and has identified core competencies, a Code of Conduct, credentialing and ongoing professional development. Coaching has been described as a "principle-shaped ontological stance and not a series of techniques" [4].

During the field experiences used for this paper, the University Facilitator was also a certified Coach. The "value added" to the pre-service teacher was realized as the University Facilitator/Coach used a "coach approach" during their work with the preservice teacher. In this approach, the University Facilitator/Coach helped to bridge theory and practice of teaching in context in a sustainable and 
meaningful way, encouraged reflection, uncovered beliefs and values, and fostered engagement and commitment to teaching for the pre-service teachers while in the classroom context. Coaching is characterized by the use of open-ended questions that evolve from the reflection of the pre-service teacher, and are directly related to the context and thoughts expressed. Coaching conversations are characterized by action planning. In the pre-service context, the coaching facilitated and extended the reflective pedagogy taught to the pre-service teachers when they attended classes at the University of Alberta. During the 14 week field experience, both approaches (clinical supervision and coaching) were used flexibly by the University Facilitator/Coach, with a focus on the development of the knowledge, skills and attributes required for teachers in Alberta. The following table summarizes the comparison between clinical supervision and coaching.

Table 1. Comparison of Clinical Supervision and Coaching

\begin{tabular}{|l|l|l|}
\hline Comparison & $\begin{array}{l}\text { Clinical } \\
\text { Supervision } \\
\text { (Evaluator, } \\
\text { Mentor) }\end{array}$ & $\begin{array}{l}\text { Coaching } \\
\text { (Facilitator/Coach) }\end{array}$ \\
\hline Initiated & $\begin{array}{l}\text { Evaluator, for } \\
\text { specific } \\
\text { purpose }\end{array}$ & $\begin{array}{l}\text { By both facilitator } \\
\text { and pre-service } \\
\text { student }\end{array}$ \\
\hline Process & $\begin{array}{l}\text { Meet, } \\
\text { determine } \\
\text { objectives, } \\
\text { observe, } \\
\text { report }\end{array}$ & $\begin{array}{l}\text { Determine focus, } \\
\text { seek solutions, } \\
\text { commit to action }\end{array}$ \\
\hline Outcome & $\begin{array}{l}\text { Data, } \\
\text { checklists, } \\
\text { may lead to } \\
\text { change in } \\
\text { practice }\end{array}$ & $\begin{array}{l}\text { Commitment to } \\
\text { change and action, } \\
\text { recursive process }\end{array}$ \\
\hline Foundation & $\begin{array}{l}\text { Assessment } \\
\text { May be in } \\
\text { response to } \\
\text { deficit }\end{array}$ & $\begin{array}{l}\text { Self-generated, } \\
\text { strength based }\end{array}$ \\
\hline Change & \begin{tabular}{l} 
Confidential \\
\hline
\end{tabular} & \\
\hline
\end{tabular}

The following discussion will highlight the results of using a "coach approach" to support and generate thoughtful reflection with pre-service teachers. The areas that will be discussed evolved from themes expressed in conversation, written lesson reflections and self-evaluations occurring during the pre-service experience. Confidentiality is essential to the coaching relationship, and as a result, no student names will be used.

\section{Coaching Methodology and Pre- Service Teaching}

The intent of implementing coaching was to assist the pre-service students to uncover the beliefs they held about teaching as a profession, their own personal understanding of the role of the teacher, beliefs about the culture of the school and the preservice teacher's contribution to the school culture with colleagues and students in the classroom context. Coaching builds from reflection, is always situated in context, and is action oriented. Coaching provided a vehicle for the pre-service teachers to situate their beliefs in the real world of teaching. Following coaching, the pre-service teachers feel more confident in setting a next step goal to follow and act upon.

A safe and confidential partnership was deliberately fostered between the University Facilitator/Coach and pre-service teacher. The aim of coaching was to examine the life-changing experience of the field experience to improve and understand the pre-service teacher's outlook, build commitment to teaching, tap into their potential, and unlock creativity and productivity.

The intent of coaching is to bring forth sustainable change in reflective practice. (It is important to note that coaching should not be used in a situation where there is a performance concern.) There are a number of reasons why coaching could be of benefit with career changing teachers, including: support for change, uncovering fundamental questions that lead to ongoing professional reflective practice, examining the alignment of theory and practice, examination of action, building competence in a new activity based on need, and willingness to change and implement innovative practice in increasingly complex educational settings. These are important skills useful in education that are typically not part of the ongoing practice in the trades. In practice, all educators would benefit from receiving coaching.

Three coaching outcomes that are relevant to successful teaching practice are as follows: Longterm excellent performance, self-correction, and selfgeneration [5]. These were evident in the pre-service teacher's experience and are noted below.

\subsection{Long-term excellent performance}

Encouraging a commitment to the profession in both teaching practice and in the trade is fundamental to career changing tradespeople. Reflection is an essential practice for all teachers, and particularly important for teachers who are the sole practitioner in their trade area. The University of Alberta prepares teachers to be reflective practitioners and life-long learners. Coaching 
uncovered this finding for the majority of the preservice teachers. Initially, many of the preservice teachers noted that they did not truly understand the dedication of experienced teachers to continually develop their skills. As the practicum continued, this new understanding about teaching was captured in a weekly reflection:

"I want to be that teacher that is continually assessing and working at always improving no matter how long I am in this profession, and be able

to reflect on it all in an open and honest way."

\subsection{Self-correction}

Self-correction is essential in assessing each day's learning. Observations of the lesson and classroom student performance inform subsequent lessons. Self-correction is essential in the complex environment of the lab/shop. Walking into the shop, an observer sees a multitude of activities taking place: use of a variety of power tools, welding torches, metals, ovens, hair solutions, etc. It was observed that the High School shop environment is more like a busy kindergarten classroom than a "traditional" High School classroom. The preservice teachers must constantly reflect about their lessons, relative to the performance and outcomes demonstrated by the classroom students. Wellcoached pre-service teachers can observe when they are performing well and when they are not, and will make any necessary adjustments independently of the coach.

\subsection{Self-generating teachers}

Self-generating teachers are team players who continually seek ways to improve their practice with their trade and in the craft of teaching. The CTS teacher is part of the school's teaching culture, but often isolated in their teaching assignment as the sole teacher for their trade in a school. They must both learn and refine the craft of teaching, discipline, management, student development and relationship, while continually reconnecting, remaining current and developing teaching skills in their trade craft. The pre-service teachers often became the link to current trade practice, as they linked the teaching experience with the world of work.

\section{Themes}

Numerous themes emerged during the practicum experiences for these pre-service teachers. In the next section, we will highlight four prominent themes: bridging theory and practice, commitment to the work of teaching, the interplay and relationships between colleagues and finally, the relationship between the classroom students and preservice teacher.

\subsection{Bridging Theory and Practice}

For these pre-service teachers, the bridge between theory and practice was also framed in the world of the work in the trade. There was a vast gap between many of the pre-service teacher's view of the world of work and what was being taught in the schools, often described by the pre-service teachers as the "real world" of the trades. For example, the preservice teachers were aware in an abstract sense, of the wide variety of reasons that students choose to take a "shop" course in the High School program. They recognized that some of the students were there to learn a skill, or have some skill to apply at a very basic level (such as changing the tires or oil in their own vehicle, or learning to cook). Some students enrolled to get an "easy credit" for their High School Certificate and graduation requirements. Some students were enrolled to gain skills for future work or training. Working in the teaching situation with this wide variety of students was often a challenge for the pre-service teachers.

Similarly, the lesson planning formats taught at University were not always practical for their work in the schools. Much of the classroom learning in the trades would be best described as "just in time" learning, that cannot be planned in advance. The theoretical need to plan coupled with the reality of the shop was often a source of dissonance for the pre-service teachers.

In addition to planning, the curriculum was a source of both inspiration and frustration for the preservice teachers, many of whom had recently left the work world. Several expressed surprise at the depth of expectations in each module, and the relatively limited time that they had to teach each module during their practicum. Each of the schools and mentor teachers had a variety of methods to address the curriculum expectations. Most commonly, projects or tasks were selected to provide hands-on practice and address a wide variety of curriculum expectations. The projects had been used from year to year. In some cases, pre-service teachers were given the opportunity to create appropriate and rigorous project assignments that led to a variety of components and linked these to curricular assessment.

Questions that were used to uncover beliefs and help the pre-service teachers to discover their understanding of the bridge between theory and practice included:

What do you believe is the role of the curriculum? How can you clarify your beliefs about the projects?

How do you expand what is possible?

\subsection{Commitment to the Work of Teaching}

It was evident that each pre-service teacher had a unique and individual reason for career change [6]. 
Many had been encouraged to change their career path based on observations of others about them as individuals. Comments such as "You would make a great teacher," were often cited as a reason for the career change.

Initially several conveyed the need for improved transmission of knowledge, having received apprentices unprepared for the world of work. Others indicated that they believed that the work of a

teacher seemed to be much easier than the trade world, and therefore a good choice for their work evolution. A number cited work/life balance. Several felt that their previous work life did not provide the meaning and gratification they sought, and felt that teaching would provide a more meaningful profession. Once uncovered, the "why" became an important philosophical signpost for action.

Coaching questions that centered on purpose were essential for each student to surface their personal "Why" at their particular age and stage of life. Questions such as the following were used to explore this purpose:

- What led you to teaching?

- What is your vision for your future work?

- What will fulfill you in the teaching role?

\subsection{Interplay and Relationships between Colleagues and the Pre-Service Teacher}

As the pre-service teachers became involved more and more in the role of "teacher" in their various schools, many questions surfaced about themselves relative to their mentors. A number of the mentor teachers were strong role models as master teachers. The pre-service teachers were inspired to watch these mentors, aspiring to try techniques they observed being used effectively. As noted by one student,

"I was confident in my trade skill level before coming into my AFX (Advanced Field Experience); it has been a learning experience working with teachers from different backgrounds and

Several of the pre-service teachers questioned practices used by their mentor teachers. Discipline, communication with students, and outdated trade practices and materials being used in aging shops were most often cited as surprises and frustrating challenges.

In some cases, the pre-service teachers attempted to introduce and improve practices, with mixed acceptance and results. Situations such as this provided a great deal of opportunity for coaching and reflection. Uncovering these challenges became an excellent opportunity for the pre-service students to clarify their beliefs and vision for themselves when they "became the teacher".
Questions that were used to uncover beliefs and help the pre-service teachers to move forward included:

- What are your next steps?

- What is your action plan?

- What do you need to do to set clear boundaries on this situation?

\subsection{Relationships between the Pre-Service Teacher and Classroom Students}

The final observation was that the pre-service teachers found particular joy and gratification when working with the classroom students. They found their classroom students appreciative of their expertise. The pre-service teachers felt a deep sense of satisfaction when working with students who they felt they understood. Often, they saw themselves reflected in the attitudes and behaviors of their students. The comment "I was just like that (student) when I was in school," was common. Each one of the pre-service teachers encountered many questions about student discipline, and school policies relative to classroom students. Each preservice teacher was intent on creating a positive working relationship with every student in their classes. Beyond the value of the positive personal relationships, the pre-service teachers noted that their trade was a key for student success in school and life.

Questions that were used in this area included:

- What strategy do you think will work best?

- Where did you feel success?

- How can you bring that forward to the future? What do you need to consider as you plan your next steps?

One pre-service teacher summarized the interplay between the curriculum, classroom student and themself as a pre-service teacher relative to the above themes as follows:

"I do know that I will leave this school having been very successful at achieving what I set out to do, and that I made real life, honest connections with these kids."

\section{Engagement in Teaching}

The following is a sample of the many comments found in the pre-service teacher's writing during their experiences in the schools. They indicate the depth of thought and reflection that resulted from their experience as they stepped into the teaching role.

"I think that the most important thing that I learned from this experience is that teaching is 
without a doubt what I want to do for the rest of my life."

"I feel that personal reflection is important as at teacher. I keep a daily journal of events that happened at home and a work, and I feel this helps me stay fresher than I normally would if I did not think of ways to be better than I was the day before. As a teacher, I feel that by reflecting after a unit gives you an opportunity to adjust lesson and unit plans to ensure top quality instruction is used in the classroom. “

"I feel that I have made a real difference to a majority of the students that I have worked with on a day to day basis by demonstrating and teaching real world skills that these students will take with them when they leave high school."

\section{Conclusion}

Many influential voices contribute to the education and impact for all pre-service teachers. From the University Instructional Team, Mentor

Teacher, Sponsoring Schools, University Facilitator/Coach, to friends and family, each person contributes to the success of the pre-service teacher. When tradespeople transfer to the teaching role, coaching was shown to have a positive impact with the pre-service teachers in the Bridge to Teacher Certification program. Coaching added a focused process to create teaching habits that will continue throughout their teaching career. Coaching was a positive addition to students transitioning in their careers to help them understand and appreciate the important roles that they could play in educating students in the trades. Further, it facilitated them in becoming thoughtful and reflective teachers, the qualities associated with excellence and ongoing professional growth and development. Questions that remain to be investigated include: What is the long-term impact on teaching practice of these coached pre-service students? How will their framework for their personal reason for becoming a teacher evolve as they work as teachers in the school system? What actions will they take to continue to grow in their dual crafts: teaching and their respective trade? And finally, What supervisory practices best support Tradeperson, pre-service teachers to develop as teachers in their new role?

\section{Acknowledgements}

We would like to thank our colleagues, preservice teachers, and mentor teachers, who have inspired us to try new strategies, and allowed us to walk alongside them in their learning journeys as educators. We are grateful for their generous welcome into their classrooms and trade shops and their willingness to allow us to observe how they strive to be teachers who make a difference in the lives of students.

\section{References}

[1] Alberta Education, https://education.alberta.ca/ bridge-to-teachercertification/bridge-to-teachercertification-program/. (Access date: 4 November 2017).

[2] Mentor Teachers, https://fieldexperiences. ualberta.ca/mentor-teachers. University of Alberta. (Access date: 12 October 2017).

[3] Where the love of coaching begins and never ends, ICF, https://coachfederation.org. (Access date: 8 November 2017).

[4] Flaherty, J., (2010) Coaching: Evoking Excellence in Others, Routledge.

[6] Mature Students Experiences and Family Life, (2010). http://acmaps.info.yorku.ca/files/2012/ 07/Mature-Students-Experiences-and-Family-Life2010.pdf. (Access date: 6 November 2017). 